Original Article

Orthopedics and Traumatology
Medical Journal of Islamic World Academy of Sciences

doi: 10.5505/ias.2019.379292 2019;27(2): 40-43

\title{
Does fixation of fibular fractures accompanying distal tibial fractures affect the ankle stability?
}

\author{
Fırat FiDAN', İsmail Ayder GÜLTEN', Cengiz KAZDAL², Akif KURTAN², Abdülkadir POLAT² \\ ${ }^{1}$ Department of Orthopedics and Traumatology, Sancaktepe Şehit Prof. Dr Ilhan Varank Education And Research Hospital, Istanbul, Turkey \\ ${ }^{2}$ Department of Orthopedics and Traumatology, Gaziosmanpasa Taksim Education And Research Hospital, Istanbul, Turkey \\ Correspondence \\ Firat FIDAN \\ Sancaktepe Şehit Prof. Dr. İlhan Varank Eğitim ve Araştırma Hastanesi, İstanbul, Türkiye \\ e-mail:drfiratfidan@gmail.com
}

\begin{abstract}
This study aimed to evaluate radiologically whether fixing the fibula in the case of combined distal third tibial and fibular fractures resulted in ankle instability.

This retrospective study included 39 patients (23 male and 16 female) with combined distal tibial and fibular fractures. All fractures were treated with plate versus intramedullary nail without fibular fixation. The radiologic images of patients were reviewed, and the radiologic ankle stability was assessed. For radiologic ankle stability, medial distance, overlap distance of the tibia and fibula, and also tibiofibular gap distance during the ankle x-ray examination were measured. The American Orthopaedic Foot and Ankle Society (AOFAS) score was used for the clinical evaluation.

The mean age of patients was 41 (17-68) years. The fracture type according to the AO/OTA classification was detected as $42 \mathrm{~A} 1$ in 18 patients, $42 \mathrm{~A} 2$ in 12 patients, and $42 \mathrm{~A} 3$ in 9 patients. None of the patients had radiological instability. The mean AOFAS score was $89.4(60-100)$.

Fixing the fibular fracture in combined distal tibialand fibular fractures did not cause ankle instability radiologically regardless of the fixation method.
\end{abstract}

Key words: Ankle instability, AOFAS, combined distal tibial and fibular fracture

\section{INTRODUCTION}

The aim of the surgical fixation of combined distal tibial fibular fracturesis to achieve good alignment and early mobilization of the patient (1). Various types of osteosyntheses are available for the sefractures. The fixation methods included open reduction- internal fixation, external fixation, close dreduction-intramedullary nailing, andminimally invasive plating systems $(2,3)$. Every method has its own advantages and disadvantages, with no consensus for the best fixation method (2-4).

The fixation of the fibula is another issue incombined distal tibial fibular fractures $(5,6)$. Some studies showed no additional advantage of the fixation of distal third fibular fractures, while others believed that the fixation of fibular fractures led to more fracture stability, resulting in malrotation and preventing the loss of reduction (5-7).
The aim of the present study was to assess the role of the fixation of the fibular fracture in ankle instability in combined distal third tibial and fibular fractures.

\section{MATERIALS AND METHODS}

This study included 39 patients ( 23 male and 16 female) with distalthirdtibialandfibularfractures, wh owereoperatedduring 2007-2014 in the clinic using eitherthe distal medial anatomic tibial plate or intramedullary tibial nail method. Fractures of the distal third tibia not reaching the joint line and fibular fractures not osteosynthesized were included in this study. Patients having previous ankle pathology and fibular fractures, which were fixed by any method, were excluded from the study. The files and radiologic images of patients were reviewed retrospectively. The mean follow-up time was 25.6 months (12-68months). Fur- 
ther, 18 patients were operate during an intramedullary nail (Fig. 1), and 21 patients were operated with a distal medial anatomic tibial plate (Fig. 2). All fractures were grouped according to the AO/OTA classification (8) preoperatively. The age, type of fracture, medial distance during the AP anklex-ray examination, tibio fibular overlapping distance, and tibio fibular distance were measured and recorded for all patients. The measurements were taken from radiographs obtained during the last follow-up period and measured in millimeters. The tibio fibular overlap and tibio fibular distances were measured $10 \mathrm{~mm}$ proximal to the joint line. More than $4 \mathrm{~mm}$ medial distance, less than $10 \mathrm{~mm}$ tibiofibular overlapping, and more than $6 \mathrm{~mm}$ tibiofibular distance were accepted as ankle instability criteria for the present study (9). The American Orthopaedic Foot and Ankle Society (AOFAS) scale was used for the clinical evaluation (10).
The SPSS program was used for statistical analysis. The Mann-Whitney $U$ test was used for parametric measures, and the chi-square test was used for nonparametrical measures. A $P$ value less than 0.05 was accepted as the significance border for statistical analysis.

\section{RESULTS}

The mean age of patients was 41 (17-68) years. The fracture type according to the AO/OTA classification wasdetected as $42 \mathrm{~A} 1$ in 18 patients, $42 \mathrm{~A} 2$ in 12 patients, and $42 \mathrm{~A} 3$ in 9 patients. Six of 39 patients were admitted to the hospital with Gustilo-Andersontype 1 fracturesand the remaining were admitted with closed fractures. Five of six open fractures were treated using a medial tibia plate, and the last one was treated with an intramedullary nail.

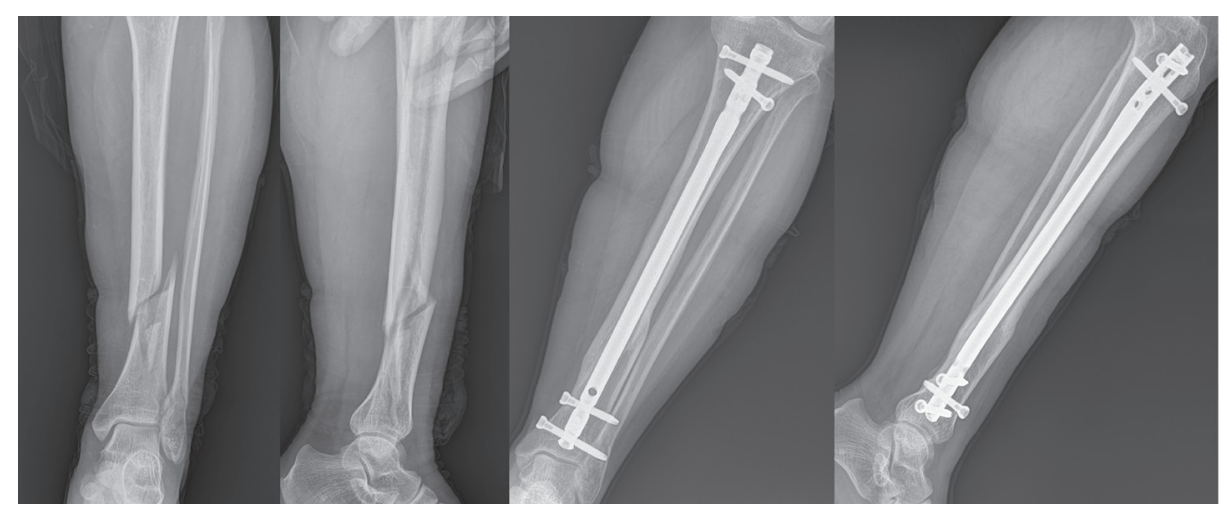

Figure 1:Preoperative radiographs and radiographs of a 56-year-old female patient in the first year of follow-up after intramedullary nailing of third distal diaphyseal tibial fracture and distal fibular fracture.

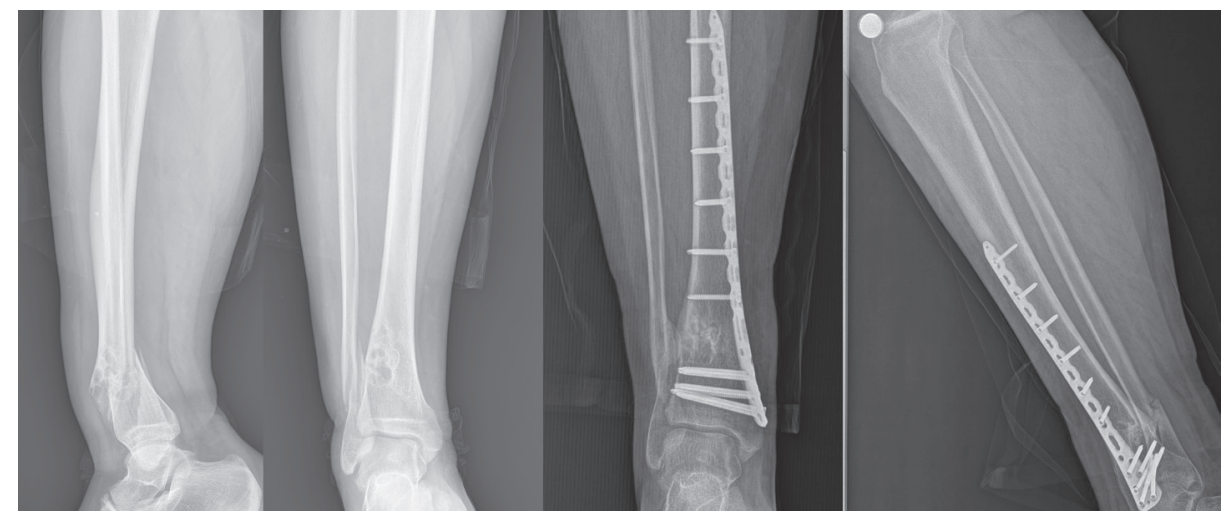

Figure 2: Preoperative radiographs and postoperative radiographs of a 19-year-old patient after plating of third distal diaphyseal tibial fracture and distal fibular fracture. 
Table 1: Radiologic measurements

\begin{tabular}{llll}
\hline & Medial distance $(\mathrm{mm})$ & Tibiofibullar overlapping $(\mathrm{mm})$ & Tibiofibullar distance $(\mathrm{mm})$ \\
\hline Intramedullar Nail & 3.7 & 10.3 & 5.8 \\
Distal medial Plate & 3.6 & 10.5 & 5.7 \\
\hline
\end{tabular}

None of the patients had radiological instability. The mean medial distance was measured as 3.7 $\mathrm{mm}(3.5-4 \mathrm{~mm})$. The medial distance for the medial plate and intramedullary nail groupswas $3.6 \mathrm{~mm}$ and $3.7 \mathrm{~mm}$, respectively. No statistically significantdifferencewas found betweenthe plate and the intramedullary nail $(P=0.179)$. The mean tibiofibular overlapping distancewas $10.4 \mathrm{~mm}$.The average tibiofibularoverlapping was $10.3 \mathrm{~mm}$ forthe intramedullary nail groupand $10.5 \mathrm{~mm}$ for the medial plategroup. Also,no statistically significant difference was detected between groups for this parameter $(P=0.181)$. The mean tibio fibular distance was calculated as $5.8 \mathrm{~mm}$. The tibiofibular distance was 5.7 $\mathrm{mm}$ for the intramedullary group and $5.8 \mathrm{~mm}$ for the medial plate group, with no statistically significant difference $(P=0.284)$ (Table 1).

The mean AOFAS score was 89.4 (60-100). It was $88.3(60-100)$ in patients treated with plate fixation and 90.5 (75-100) in patients treated with intramedullary nailing, with no significant difference between the groups $(P=0.813)$.

\section{DISCUSSION}

This study showed that the non-fixation ofthe distal third fibular fracturesdid not cause radiological instability regardless of the tibial fixation method in the surgical treatment of combined distal third tibial and fibular fractures. The fibula of none of the patients was fixed in the studygroup. All fractures healed without a problem, and no radiological instability was detected. Measuring radiological instability only with plain x-rays and having such a small patient group were limitations of the present study. More detailed measurements can be done with computerized tomography. The strength of the study was the evaluation of the radiological instability of patients besides the clinical evaluation.

Clinicians face more problems while treating distal third tibial fibular fractures compared with tibial shaft fractures(11). Thin soft tissue cover age and weak vascularization of distal third of the tibia are main problems of these kinds of fractures (11, 12). Also, patients experience more ankle pain in these fractures $(11,12)$. Previous studies evaluated the functional status of ankle after these fractures ( 2 , $3,11)$. However, the ankle was evaluated radiologically, besides the evaluation of the functional status of the ankle, in this study. No radiological instability was detected regardless of the tibial fixation method used.

Whether distal fibular fixation can add greater stability to distal third tibial fibular fractures is still controversial $(13,14)$.Götzen et al. found that the plate fixation of fibula besides the external fixation of tibia for the tibial shaft fracture added more torsional and longitudinal stability (5). Egol et al. reported that the non-fixation of the fibula increased the risk of failure of tibial fixation (15). In contrast, the non-fixation of the fibula did not cause radiological instability in the ankle.

No significant difference was found in ankle radiologic stability and AOFAS score, whether tibial fixation was done using a plate or an intramedullary nail. Both groups displayed satisfactory results.

\section{CONCLUSIONS}

This study concluded that the fixation of the fibular fracture accompanying distal tibial fractures was not crucial because no ankle instability was observed radiologically and clinically all patients were satisfied with the results. The limitation of the study was its small sample size.

\section{REFERENCES}

1. Kasper W. Janssen\& Jan Biert\& Albert vanKampen. Treatment of distal tibial fractures: plate versus nail.Aretrospective outcome analysis of matched pairs of patients. International Orthopaedics (SICOT) (2007) 31:709-714

2. Zelle BA, Bhandari M, Espiritu M, Koval KJ, Zlowodzki M(2006) Treatment of distaltibiafractureswithoutarticularinvolvement: a systematicreview of 1125 fractures. J OrthopTrauma 20:76-79 
3. Pierre Joveniaux and Xavier Ohl and Alain Harisboure et al. Distal tibia fractures: management and complications of 101 cases. International Orthopaedics (SICOT) 2010; 34:583-588.

4. Marsh JL, Saltzman CL. Ankle fractures. In: Rockwood and Greens fractures in adults. Ed by Bucholz RW, Heckman JD, Court-Brown CM, 6th edn. Lippincott Williams and Wilkins, Philadelphia, 2006, pp 2147-2247.

5. Gotzen L, Haas N, Hutter J, Koller W. [The importance of the fibula for stability in plateosteosynthesis of thetibia]. Unfallheilkunde. 1978;81:409-16. German

6. Morrison KM, Ebraheim NA, Southworth SR, Sabin JJ, Jackson WT. Plating of the fibula. Its potential value as an adjunct to external fixation of the tibia. Clin Orthop 1991; 266:209-213.

7. Weber TG, Harrington RM, Henley MB, Tencer AF. The role of fibul arfixation in combined fractures of the tibia and fibula: a biomechanical investigation. J Orthop Trauma 1997;11:206-11.

8. Marsch JL,Slongo TLAgel J et al. Fracture and dislocation classification compendium-2007: Orthopaedic Trauma Association classification, database and outcomes committee. J Orthop Trauma. 2007; 21(10 Suppl):S1-133.

9. Harper $M$, Keller T. A radiographic evaluation of the tibio fibular syndesmosis. Foot Ankle 1989; 10:156-60.
10. Kitaoka HB, Alexander IJ, Adelaar RS et al. Clinical rating systems for the ankle-hindfoot, midfoot, hallux, and lesser toes. Foot Ankle Int 1994;15:349-53. 10.1177/107110079401500701

11. Yavuz U, Sökücü S, Demir B, Yildirim T, Ozcan C, Kabukçuoğlu YS. Comparison of intramedullary nail and plate fixation indistal tibia diaphyseal fractures close to the mortise. Ulus Travma Acil Cerrahi Derg 2014; 20(3):189-93.

12. Yang SW, Tzeng HM, Chou YJ, Teng HP, Liu HH, Wong CY. Treatment of distal tibial metaphyseal fractures: Plating versuss hortened intramedullary nailing. Injury 2006;37:531-5.

13. Teitz CC, Carter DR, Frankel VH. Problems associated with tibial fractures with intact fibulae. J Bone Joint Surg Am 1980;62:7706.

14. Kumar A, Charlebois SJ, Cain EL, Smith RA, Daniels AU, Crates JM. Effect of Fibular Plate Fixation on Rotational Stability of Simulated Distal Tibial Fractures Treated with Intramedullary Nailing. J Bone Joint Surg Am 2003; 85(4):604-8.

15. Egol KA, Weisz R, Hiebert R, Tejwani NC, Koval KJ, Sanders RW. Does fibular plating improve alignment after intramedullary nailing of distal meta physeal tibia fractures? J Orthop Trauma 2006; 20(2):94-103. 